\title{
The morphological changes upon cryomilling of cellulose and concurrent generation of mechanoradicals
}

\author{
Özge Laçin a, ${ }^{\text {, }}$, Joanna Kwiczak-Yiğitbaşı ${ }^{\text {a, }}{ }^{1}$, Meltem Erkan ${ }^{a}$, Şevki Can Cevher ${ }^{\text {b }}$, \\ Bilge Baytekin ${ }^{\mathrm{a}, \mathrm{c}, *}$ \\ a Department of Chemistry, Bilkent University, Ankara, 06800, Turkey \\ b Department of Chemistry, Middle East Technical University, Ankara, 06531, Turkey

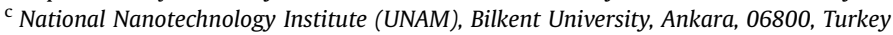

\section{A R T I C L E I N F O}

\section{Article history:}

Received 4 April 2019

Received in revised form

5 August 2019

Accepted 13 August 2019

Available online 19 August 2019

\section{Keywords:}

Mechanoradicals

Cellulose

Ball-milling

Cryomilling

Mechanochemistry

\begin{abstract}
A B S T R A C T
With mechanical input, chemical bonds in polymers can be broken. Recently, it was shown that reactive ends formed by homolytic cleavage, so-called mechanoradicals, can be used in driving further chemical reactions or in making new composite materials. Cellulose, the most abundant polymer on earth, can also be subjected to mechanical input via ball-milling to produce mechanoradicals. Despite many reports on morphological changes in cellulose upon milling, there is only a limited understanding on how these changes affect the mechanoradical production, i.e., in which domains of cellulose the bonds are broken to produce the mechanoradicals. Here we show, the effect of the initial morphology of cellulose (cotton or microcrystalline cellulose) and the mode of grinding (dry or solvent-assisted) on the amount of generated cellulose mechanoradicals. The morphological and the chemical changes taking place upon milling of cellulose are monitored by SEM, XRD, and ATR, and the number of mechanoradicals is determined by a first-time quantitative analysis of cellulose mechanoradicals using radical scavenger DPPH. Our findings can help in efficient mechanofunctionalization of cellulose and to make useful mechanochemical reactions of cellulose using mechanoradicals, which stand as a promising economic and environmentfriendly alternative to the conventional solvent-assisted chemistry of cellulose.
\end{abstract}

(C) 2019 Published by Elsevier Ltd.

\section{Introduction}

Cellulose is the most abundant biopolymer in nature, which contains linear chains of repeating D-glucose molecules connected by $\mathrm{C}-\mathrm{O}-\mathrm{C}$ bonds named as $\beta-1,4-$ glycosidic linkages [1]. Over the past decades, due to growing interest in sustainability and green chemistry, cellulosic materials have received attention, since cellulose is highly abundant, lightweight, strong, biodegradable material, and because composite materials including cellulose can be environment-friendly, biocompatible, low cost, low weight, and multifunctional. For functionalization of cellulose and obtaining large-scale cellulose composites, mechanochemistry stands as a straightforward and green alternative [2-8]. Since 1921 it is known that when cellulose is subjected to mechanical input, its fibrils

\footnotetext{
* Corresponding author. Department of Chemistry, Bilkent University, Ankara, 06800, Turkey.

E-mail addresses: bbaytekin3@gmail.com (Ö. Laçin), b-baytekin@fen.bilkent. edu.tr (B. Baytekin).

1 Ö.L. and J.K-.Y. contributed equally.
}

disintegrate physically. Cellulose mechanochemistry, on the other hand, breaks the chemical bonds in cellulose by mechanical input [9-11]. When cellulose is ball-milled, 1) the intermolecular hydrogen bonds and 2 ) covalent bonds ( $\mathrm{C}-\mathrm{O}-\mathrm{C}$ glycosidic bonds and $\mathrm{C}-\mathrm{C}$ bonds) are broken, and mechanoradicals are produced. There are several examples of mechanofunctionalization by using the generated 'broken ends'; for example, by breaking intermolecular hydrogen bonds in cellulose and using free $\mathrm{OH}$ groups formed, esterification of cellulose was achieved [2-4]. On the other hand, by breaking the covalent bonds of cellulose, mechanoradicals can be produced (Fig. 1a), which can be verified and analyzed by Electron Spin Resonance spectroscopy (ESR) (Fig. 1b) [5-11]. Such mechanoradicals formed by the bond cleavages of polymers upon ball milling were firstly examined with ESR spectroscopy by Butyagin et al. in 1964 [12]. Later, by Sakaguchi and Sohma, a special ball-milling apparatus was designed for ESR analysis of polymer mechanoradicals [13]. In this setup, there is a direct connection between an ESR sample tube and the milling chamber under vacuum, which helps to proceed to the following ESR 
a

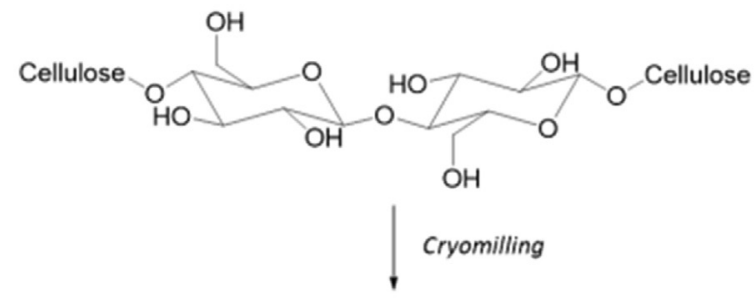

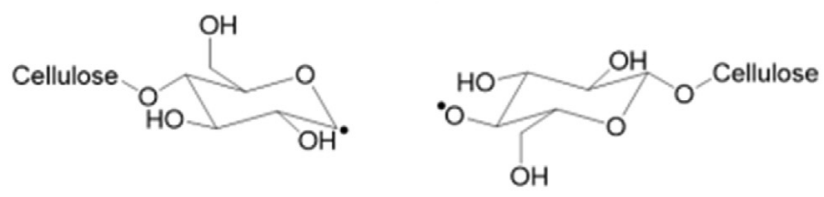<smiles>CC(C)(C)O[Ge]OC(O)C1COC([O])C(O)C1O</smiles><smiles>OC[C@@H]1OC[C@@H](O)[C@H](O)C(O)O1</smiles>

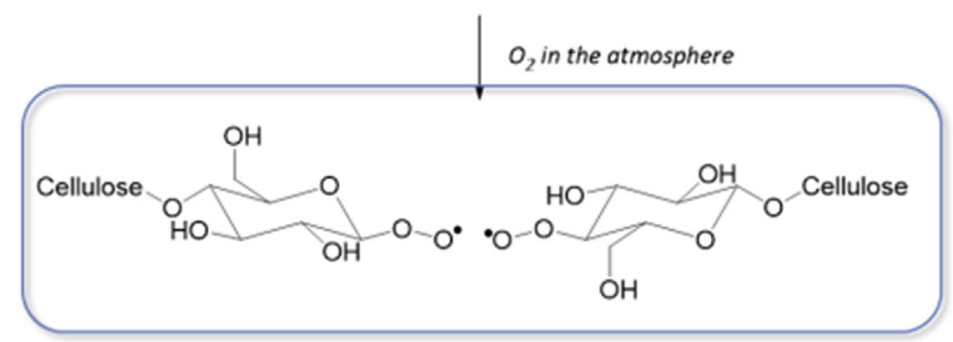

b

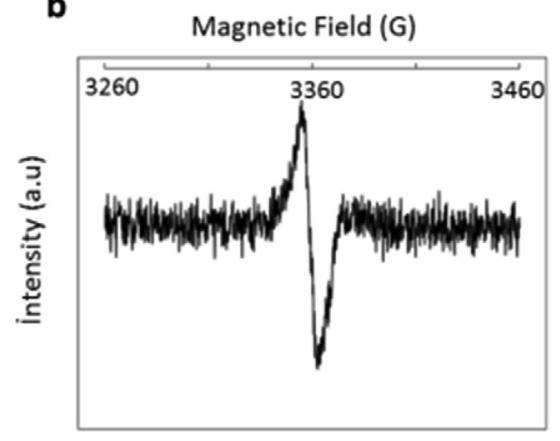

c
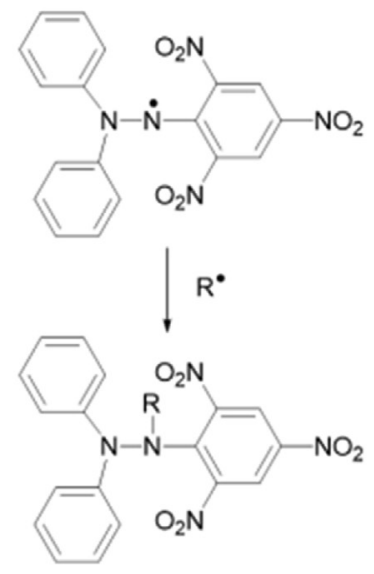

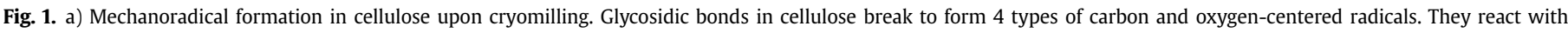

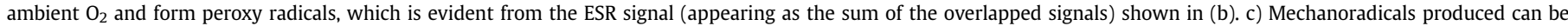

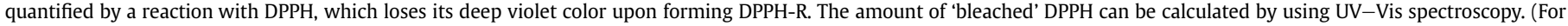
interpretation of the references to color in this figure legend, the reader is referred to the Web version of this article.)

measurement without any sample exposure to air. Also, samples can be milled at cryo-conditions; the temperature of the sample tube is not let to increase before and during the ESR measurement, which is essential for detection of the less stable radicals. Using this method, they showed that alkyl (carbon-centered), alkoxyl (oxygen-centered), and peroxyl radicals (if the milling chamber is exposed to oxygen atmosphere during milling) are produced upon covalent bond breaking in cellulose. These mechanoradicals were then used as initiators to polymerize several monomers such as methyl methacrylate [5,6], hydroxyethyl methacrylate [7], styrene [8], and to obtain synthetic polymer-cellulose copolymers.

As mentioned above, mechanochemistry of cellulose provides green, up-scalable access to cellulose functionalization and cellulose composites, however, surprisingly, so far it has only been sparsely used for these purposes. In our opinion, the reason for this rarity is the lack of studies on the mechanoradical quantification, i.e., knowing the number of produced mechanoradicals is vital for driving reactions other than polymerization, especially when the mechanoradicals should be used in stoichiometric amounts. It is also essential to know the effect of the concurrent morphological changes on the production of mechanoradicals in the cellulose matrix. With this study, we try to provide answers to these points. First, we analyze the formation of cellulose mechanoradicals in two morphologically different samples of cellulose, i.e., cotton, which has long (up to mm-length) fibers, and microcrystalline cellulose, which has fibers of a few hundred microns. We use cryomilling to generate mechanoradicals in cellulose and determine their amount through reaction with a radical scavenger, 2,2-Diphenyl-1- picrylhydrazyl (DPPH), which loses its deep violet color (abs max. $519 \mathrm{~nm}$ ) upon reacting with radicals [14-18]. In this study, we do not use inert atmosphere conditions in the production and the detection of the mechanoradicals since these conditions are not applicable in most practical instances, upon up-scaling or industrial mechanochemical processes.

We have shown in our previous studies, the generation of mechanoradicals in some common synthetic polymers, their further chemical reactions [14,19], and how they affect the generation and stabilization of static charges on polymer surfaces $[15,16]$. In those studies, we have adapted the literature procedure given for alumina and quartz [17,18] and frequently used 'DPPH-radical scavenging' as a reliable method for quantification of mechanoradicals in polymers generated during/after mechanoradical treatment (Fig. 1c) [14-16]. Using a similar procedure, in this study, we determined the number of mechanoradicals produced in cellulose upon solvent-assisted milling (a method that does not cause a significant change the crystallinity of the samples, because of 'dampening action' [20]) and 'dry' milling (upon which percent crystallinity of the samples are changed drastically). In parallel, we monitored the morphological changes in cellulose during mechanical treatment with SEM, FTIR-ATR, and XRD - common tools used for tracking cellulose and polymer mechanodegradation. We show, even without a significant change in crystallinity upon milling, cellulose samples can produce significant number of radicals-because of the bond-breakages occurring predominantly at the amorphous domains. On the other hand, a greater number of mechanoradicals are produced when crystalline domains are 
transformed into amorphous regions during (dry) milling.

\section{Experimental}

\subsection{Materials}

As cellulose sources, cotton (100\% pure) from a direct commercial source and microcrystalline cellulose (MCC, $50 \mu \mathrm{m}$ ) from Acros Organics were used. 2,2-Diphenyl-1-picrylhydrazyl (DPPH), alkali lignin and acetonitrile solvent were supplied by SigmaAldrich.

\subsection{Moisture content}

Moisture content was examined by placing cotton and MCC samples into a vacuum oven and controlling the loss of mass during five days at $50{ }^{\circ} \mathrm{C}$ at low vacuum. There was no detectable amount of moisture for the cellulose material used in the experiments.

\subsection{Grinding}

Samples were milled with six zirconia balls with $10.06 \mathrm{~mm}$ diameter in zirconia chamber ( $25 \mathrm{~mL}$ volume) using a Retsch Cryomill instrument. In a typical experiment, the cellulose samples were milled at $30 \mathrm{~Hz}$ (milling at a lower frequency, e.g., $15 \mathrm{~Hz}$, values generated a lower number of radicals than at $30 \mathrm{~Hz}$ ) for a given milling time (see individual experiments below) at $77 \mathrm{~K}$ (cryo condition). This low temperature is achieved by circulating liquid nitrogen around the milling chamber, keeping its temperature at $77 \mathrm{~K}$. Due to low temperature, lifetimes of the produced mechanoradicals are enhanced, and samples in the chamber can be milled without sticking on the wall of the chamber. Moreover, using balls and chamber made up of zirconia allows us to mill the samples in the chamber without contamination due to wearing and sticking of zirconia on cellulose samples. Each milling run was repeated at least three times in order to calculate the standard deviation.

\subsubsection{Grinding with solvent ('solvent-assisted grinding')}

$500 \mathrm{mg}$ of cotton or microcrystalline cellulose (MCC) were milled with $2.5 \mathrm{~mL}$ of $1.3 \times 10^{-3} \mathrm{M}$ of DPPH solution in acetonitrile for $10-60 \mathrm{~min}$. At the end of the cryomilling, the mixtures of cellulose and DPPH solution were diluted to $10 \mathrm{~mL}$ in the sample chamber, and the mixture was mixed at $5 \mathrm{~Hz}$ for $30 \mathrm{~s}$. Then, the mixtures were centrifuged, and the solution was subjected to UV-Vis spectroscopy for determination of the remaining DPPH and quantitative analysis of the produced mechanoradicals. The solid containing cellulose was washed several times with acetonitrile and dried in vacuum to examine the morphological changes and changes in crystal structure by using SEM, FTIR-ATR, and XRD (See SI for further experimental details).

\subsubsection{Grinding without solvent (“dry grinding')}

In a typical 'dry' grinding experiment, $500 \mathrm{mg}$ of the cellulose samples (cotton or MCC) were milled for $10-60 \mathrm{~min}$ by using Cryomill. After the cryomilling, $2.5 \mathrm{~mL}$ of $1.3 \times 10^{-3} \mathrm{M}$ DPPH solutions prepared in acetonitrile were added on the milled sample. Then the mixture was diluted to $10 \mathrm{~mL}$ by adding acetonitrile and centrifuged. $0.5 \mathrm{~mL}$ of supernatant containing DPPH solution was diluted to $5 \mathrm{~mL}$ with acetonitrile. A control solution of DPPH in acetonitrile was also prepared with $[\mathrm{DPPH}]=3.2 \times 10^{-5} \mathrm{M}$. Thoroughly washed (acetonitrile), and vacuum-dried cryomilled cellulose samples were analyzed for morphological, structural, and compositional changes by SEM, FTIR-ATR, and XRD. ESR Spectroscopy was also employed to monitor the production of radicals and their qualitative analyses of cotton.

\subsection{Synthesis of acetylated ground MCC and cotton samples}

The acetylation was based on the reported method [21]. A mixture of acetic acid $(0.052 \mathrm{~mol})$ and trifluoroacetic anhydride $(0.029 \mathrm{~mol})$ was stirred at $50^{\circ} \mathrm{C}$ for $20 \mathrm{~min}$. Then cellulose source (MCC, MCC ground for 10, 20, 30, 40, and $60 \mathrm{~min}$, cotton and cotton ground for $10,20,30,40$, and $60 \mathrm{~min})(0.1 \mathrm{~g})$ was added to the solution, and the mixture was stirred at $50{ }^{\circ} \mathrm{C}$ for $14 \mathrm{~h}$. The clear paleyellow solution was then poured into methanol, the precipitate was filtered, and dried under vacuum at $50{ }^{\circ} \mathrm{C}$.

Acetylated MCC: ${ }^{1} \mathrm{H}$ NMR $\left(400 \mathrm{MHz}, \mathrm{CDCl}_{3}\right): \delta=5.09-5.05(\mathrm{~m}$, 3-H), 4.81-4.77 (m, 2-H), 4.42-4.36 (m, 1-H, 6-H), 4.07-4.04 (m, $\left.6^{\prime}-\mathrm{H}\right), 3.72-3.69(\mathrm{~m}, 4-\mathrm{H}), 3.54-3.52(\mathrm{~m}, 5-\mathrm{H}), 2.12-1.93(\mathrm{~m}$, $\mathrm{OCOCH}_{3}$ ) ppm. (Fig. S1a).

Acetylated-ground $10^{\prime}$ MCC: ${ }^{1} \mathrm{H}$ NMR (400 $\left.\mathrm{MHz}, \mathrm{CDCl}_{3}\right)$ : 5.09-5.06 (m, 3-H), 4.81-4.77 (m, 2-H), 4.43-4.36 (m, 1-H, 6-H), 4.07-4.05 (m, 6'-H), 3.73-3.69 (m, 4-H), 3.55-3.52 (m, 5-H), 2.13-1.94 (m, $\left.\mathrm{OCOCH}_{3}\right)$ ppm. (Fig. S1b).

Acetylated-ground $20^{\prime}$ MCC: ${ }^{1} \mathrm{H}$ NMR $\left(400 \mathrm{MHz}, \mathrm{CDCl}_{3}\right)$ : 5.09-5.06 (m, 3-H), 4.81-4.77 (m, 2-H), 4.43-4.36 (m, 1-H, 6-H), 4.08-4.05 (m, 6'-H), 3.74-3.69 (m, 4-H), 3.56-3.52 (m, 5-H), 2.13-1.94 (m, $\left.\mathrm{OCOCH}_{3}\right)$ ppm. (Fig. S1c).

Acetylated-ground $30^{\prime}$ MCC: ${ }^{1} \mathrm{H}$ NMR $\left(400 \mathrm{MHz}, \mathrm{CDCl}_{3}\right)$ : 5.09-5.06 (m, 3-H), 4.81-4.77 (m, 2-H), 4.43-4.36 (m, 1-H, 6-H), 4.08-4.05 (m, 6'-H), 3.74-3.69 (m, 4-H), 3.54-3.52 (m, 5-H), 2.12-1.94 (m, $\left.\mathrm{OCOCH}_{3}\right)$ ppm. (Fig. S1d).

Acetylated-ground $\quad 40^{\prime} \quad$ MCC: ${ }^{1} \mathrm{H} \quad \mathrm{NMR} \quad(400 \mathrm{MHz}$, $\left.\mathrm{CDCl}_{3}\right): \delta=5.10-5.05(\mathrm{~m}, 3-\mathrm{H}), 4.82-4.77(\mathrm{~m}, 2-\mathrm{H}), 4.43-4.37(\mathrm{~m}$, 1-H, 6-H), 4.08-4.05 (m, 6'-H), 3.71-3.69 (m, 4-H), $3.55(\mathrm{~m}, 5-\mathrm{H})$, 2.13-1.95 (m, $\left.\mathrm{OCOCH}_{3}\right)$ ppm. (Fig. $\left.\mathrm{S} 1 \mathrm{e}\right)$.

Acetylated-ground $60^{\prime}$ MCC: ${ }^{1} \mathrm{H}$ NMR $\left(400 \mathrm{MHz}, \mathrm{CDCl}_{3}\right)$ : 5.09-5.06 (m, 3-H), 4.82-4.77 (m, 2-H), 4.43-4.36 (m, 1-H, 6-H), 4.08-4.05 (m, 6'-H), 3.74-3.69 (m, 4-H), 3.55-3.53 (m, 5-H), 2.12-1.94 (m, $\left.\mathrm{OCOCH}_{3}\right)$ ppm. (Fig. S1f).

Acetylated cotton: ${ }^{1} \mathrm{H}$ NMR $\left(400 \mathrm{MHz}, \mathrm{CDCl}_{3}\right): \delta=5.10-5.05(\mathrm{~m}$, 3-H), 4.82-4.77 (m, 2-H), 4.43-4.36 (m, 1-H, 6-H), 4.08-4.04 (m, 6'-H), 3.74-3.69 (m, 4-H), 3.55-3.52 (m, 5-H), 2.13-1.95 (m, $\mathrm{OCOC}_{3}$ ) ppm (Fig. S2a).

Acetylated-ground $10^{\prime}$ cotton: ${ }^{1} \mathrm{H}$ NMR $\left(400 \mathrm{MHz}, \mathrm{CDCl}_{3}\right)$ : $\delta=5.09-5.06(\mathrm{~m}, 3-\mathrm{H}), 4.81-4.77(\mathrm{~m}, 2-\mathrm{H}), 4.42-4.36(\mathrm{~m}, 1-\mathrm{H}, 6-$ $\mathrm{H})$, 4.07-4.04 (m, 6'-H), 3.77-3.69 (m, 4-H), 3.55-3.52 (m, 5-H), 2.13-1.94 (m, $\left.\mathrm{OCOCH}_{3}\right)$ ppm. (Fig. S2b).

Acetylated-ground $20^{\prime}$ cotton: ${ }^{1} \mathrm{H}$ NMR $\left(400 \mathrm{MHz}, \mathrm{CDCl}_{3}\right)$ : $\delta=5.09-5.06(\mathrm{~m}, 3-\mathrm{H}), 4.82-4.77(\mathrm{~m}, 2-\mathrm{H}), 4.43-4.36(\mathrm{~m}, 1-\mathrm{H}, 6-$ $\mathrm{H})$, 4.07-4.04 (m, 6'-H), 3.77-3.69 (m, 4-H), 3.55-3.52 (m, 5-H), 2.13-1.95 (m, $\left.\mathrm{OCOCH}_{3}\right)$ ppm. (Fig. S2c).

Acetylated-ground $30^{\prime}$ cotton: ${ }^{1} \mathrm{H}$ NMR $\left(400 \mathrm{MHz}, \mathrm{CDCl}_{3}\right)$ : $\delta=5.09-5.06(\mathrm{~m}, 3-\mathrm{H}), 4.81-4.77(\mathrm{~m}, 2-\mathrm{H}), 4.43-4.36(\mathrm{~m}, 1-\mathrm{H}, 6-$ H), 4.08-4.05 (m, 6'-H), 3.73-3.69 (m, 4-H), 3.55-3.53 (m, 5-H), 2.13-1.94 (m, $\left.\mathrm{OCOCH}_{3}\right)$ ppm. (Fig. S2d).

Acetylated-ground $40^{\prime}$ cotton: ${ }^{1} \mathrm{H} \quad \mathrm{NMR} \quad(400 \mathrm{MHz}$, $\left.\mathrm{CDCl}_{3}\right): \delta=5.10-5.06(\mathrm{~m}, 3-\mathrm{H}), 4.81-4.77(\mathrm{~m}, 2-\mathrm{H}), 4.43-4.37(\mathrm{~m}$, 1-H, 6-H), 4.08-4.06 (m, 6'-H), 3.74-3.69 (m, 4-H), 3.55-3.53 (m, 5-H), 2.13-1.95 (m, $\left.\mathrm{OCOCH}_{3}\right)$ ppm. (Fig. S2e).

Acetylated-ground $60^{\prime}$ cotton: ${ }^{1} \mathrm{H}$ NMR $\left(400 \mathrm{MHz}, \mathrm{CDCl}_{3}\right)$ : $\delta=5.09-5.06(\mathrm{~m}, 3-\mathrm{H}), 4.82-4.77(\mathrm{~m}, 2-\mathrm{H}), 4.43-4.36(\mathrm{~m}, 1-\mathrm{H}, 6-$ H), 4.07-4.05 (m, 6'-H), 3.74-3.69 (m, 4-H), 3.55-3.52 (m, 5-H), 2.13-1.94 (m, $\left.\mathrm{OCOCH}_{3}\right)$ ppm. (Fig. S2f).

\subsection{Characterization}

\subsubsection{UV-vis spectroscopy analysis}

The absorption spectra were recorded using a Cary 100 Bio UV-Visible spectrophotometer from Varian. 


\subsubsection{Scanning electron microscopy (SEM)}

The surface morphologies of cellulose samples and cellulosemetal NPs composites were imaged and analyzed with a Quanta 200F model SEM with an accelerating voltage of $5 \mathrm{kV}$. Samples were coated with $\mathrm{Au}-\mathrm{Pd}$ (thickness $0.1 \mathrm{k} \AA$ ).

\subsubsection{Electron Spin Resonance (ESR) or electron paramagnetic resonance (EPR) spectroscopy analysis}

After dry grinding of cotton samples (vide supra), produced cellulose mechanoradicals were characterized employing Bruker ELEXSYS E580 model ESR spectrometer equipped with a highsensitivity cavity and operating at X-band frequencies $(9 \mathrm{GHz})$. Measurements were performed under non-saturating conditions. Signal intensities were obtained by double integration of the baseline-corrected spectra using Bruker WinEPR software. The following experimental conditions were used: $0.3 \mathrm{~mW}$ microwave power, $0.25 \mathrm{mT}$ modulation amplitude, $41 \mathrm{~ms}$ conversion time, $41 \mathrm{~ms}$ time constant and 1024 points.

\subsubsection{Fourier transform infrared attenuated total reflectance (FTIR- ATR) spectroscopy analysis}

The chemical structure changes in cellulose after solventassisted and dry grinding of samples were investigated by infrared spectroscopy. FTIR-ATR spectra of the samples were obtained in the range of $4000-400 \mathrm{~cm}^{-1}$ with a Bruker Alpha model spectrometer with Platinum ATR crystal.

\subsubsection{X-ray diffraction (XRD) analysis}

The changes in the crystalline structure of the solvent-assisted and dry cryomilled cellulose samples were monitored by X-ray diffraction (XRD). The XRD measurements were performed on an X'Pert PRO, PANalytical model X-ray diffractometer with $\mathrm{Cu} \mathrm{K} \alpha$ radiation. $40 \mathrm{~mA}$ applied current, and $45 \mathrm{kV}$ accelerating voltage values were used.

\subsubsection{Gel permeation chromatography measurements}

The average molecular weight $\left(\mathrm{M}_{\mathrm{W}}\right)$ and the degree of polymerization were estimated by gel permeation chromatography (GPC) (RID 20A Shimadzu) in chloroform at room temperature. Cellulose samples were first acetylated in order to dissolve them in eluent used in GPC measurements. PSS SDV analytical linear M column was used, and the flow rate was $1.0 \mathrm{~mL} / \mathrm{min}$. A calibration curve was obtained using polystyrene standards.

\subsection{7. ${ }^{1} \mathrm{H}$ nuclear magnetic resonance $\left({ }^{1} \mathrm{H}\right.$ NMR $)$ measurements}

${ }^{1} \mathrm{H}$ NMR spectra were recorded on Bruker Biospin Avance 400 NMR spectrometer at $400 \mathrm{MHz}$ in $\mathrm{CDCl}_{3}$. TMS was used as an internal reference.

\section{Results and discussion}

\subsection{Identification of the mechanoradicals by ESR}

Fig. 1a shows the typical bond-breakages taking place during grinding of cellulose under inert conditions, pictured using results from previous literature ESR analyses of these radicals [22]. These radicals, which are formed mostly through the breakage of the $\beta-1,4$ glycosidic bonds, are of four types: two alkyl type-carbon centered radicals and two alkoxyl type-oxygen centered radicals (Fig. 1a). If bond breaking takes place in an oxygen atmosphere, peroxyl radicals were also reported to form, which indeed increases the lifetime of the radicals $[5,23]$. Although the chemical reactivity of peroxy radicals was reported to be lower than alkoxy and carboncentered radicals, they can drive various chemical reactions as we have shown before [14]. In our studies, we first performed a room temperature ESR analysis of the cellulose mechanoradicals formed: ESR spectrum of 40 min cryomilled cotton sample showed a singlet signal with g-value of 2.00558 (Fig. 1b). It is evident from this spectrum that initially formed cellulose mechanoradicals reacted with oxygen in the atmosphere to form secondary peroxy cellulose radicals $[5,9,24,25]$, as expected from milling in the presence of oxygen. It had previously been reported that cellulose mechanoradicals show high stability at room temperature for an extended time $[10,11]$. We observed this stability of cellulose mechanoradicals in our ESR analyses, which is a promising feature for further (room temperature) reactions with these radicals.

\subsection{Quantification of the formed mechanoradicals by 'DPPH bleaching' surveyed via UV-Vis spectra}

After solvent-assisted cryomilling of the cellulose sample (cotton or MCC) together with the DPPH solution for 10, 20,30, 40, and $60 \mathrm{~min}$, (see Experimental for details), the number of radicals were calculated using the decrease in absorption of the DPPH solution at its maximum (519 nm) (Fig. 2). Here we note, in all experiments, the cotton and the MCC samples are washed with ethanol and dried previously to remove any radicals that are already formed at the sample preparation step. We compared the absorption spectra of DPPH subjected to cryomilled samples to those of the identically prepared but not milled control sample. The former showed a decrease in the absorption of DPPH, however, for the latter the absorption of DPPH did not change significantly with time, showing hydroxyl groups in cellulose, or any minute amount of lignin present in the sample does not react with DPPH and only the generated mechanoradicals react with it. In addition, lignin impurity that might have interfered with the DPPH tests was shown to be absent in the samples by FTIR-ATR spectra (Fig. S3). DPPH solution alone was found to be thermally bleached during room temperature milling; however, DPPH does not react with acetonitrile when let to stay at room temperature (Fig. S4). Under cryo conditions, DPPH solutions can be milled without a significant change in their absorbance, proving their chemical stability under these conditions. As shown in Fig. 2b and d, with increasing milling time, the number of formed cellulose mechanoradicals increases, reaching a constant value after about 30 min of grinding in cotton samples and $40 \mathrm{~min}$ in MCC. The results show that milling cotton produces about twice more (at 40 min milling time) radicals than milling MCC. 'Dry' milling. In dry milling, DPPH solutions were added to cellulose samples after cryomilling DPPH. The radicals generated in the bulk of the cellulose sample 'migrate' towards the surface of the cellulose, possibly by a radical-driven propagation mechanism [26,27] that is similar to that reported previously in mechanically treated poly(ethylene) [28,29], polydimethylsiloxane and PVC [14]. Therefore, we allowed the samples to stay in DPPH solution for $48 \mathrm{~h}$ to allow the migration of radicals to the surface of the cellulose (Fig. S5) [14] and to give enough time to complete the reaction between mechanoradicals and DPPH. The numbers of radicals, approximately $10^{18}$ radicals per gram of cellulose, for the given milling and waiting times were then calculated from the decrease in the absorbance of the DPPH as for mechanoradicals obtained by solvent-assisted grinding (above). The number of radicals increases with increasing grinding and waiting times (Fig. 2, S5). (With prolonged grinding times, the formed radicals may recombine and/ or decay. These processes might be facilitated in presence of solvent resulting in lower number of radicals for these grinding times (after $40 \mathrm{~min}$ ) in solvent-assisted milling). Even days after milling, the 'migration' of radicals continues, though slowly, as was also reported for the mechanoradicals produced in synthetic polymers [14].

The comparison of the calculated numbers of radicals obtained 

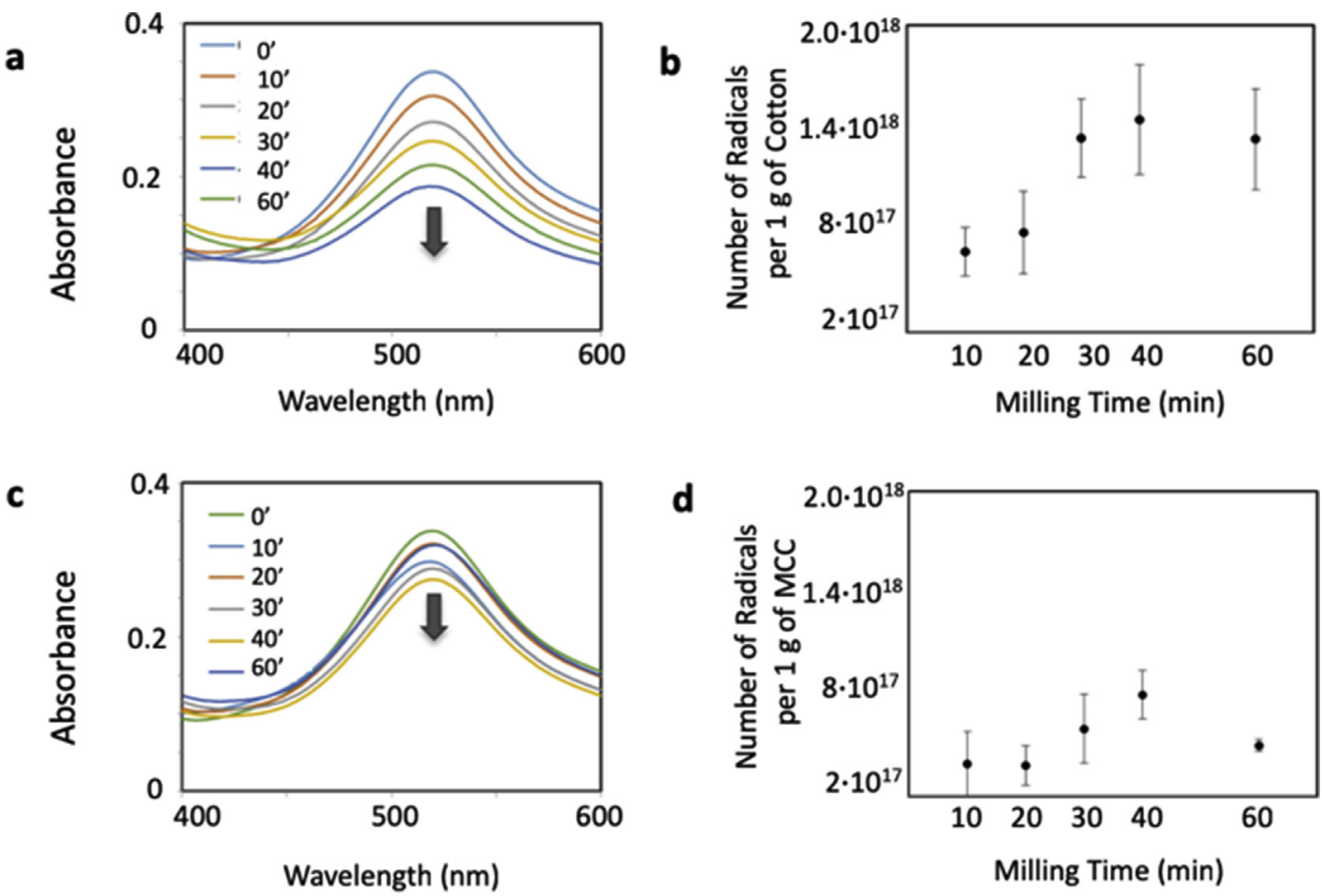

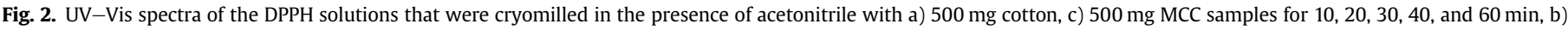
and d) number of radicals per gram of cotton and MCC, respectively, for each milling time calculated from the spectra in (a) and (c).

through 'dry' and solvent-assisted grinding (Tables 1 and 2) produced a surprising result since capturing the mechanoradicals as they form, without letting them react with oxygen or decay through solvent-assisted milling should have been more efficient than 'dry' milling. However, in our case, dry milling yielded a higher number of radicals. Previously, in a related study [20], it was shown that milling cellulose together with different solvents could lead to changes in the crystal structure of cellulose. However, in this study, there is no report on the efficiency of milling, especially in terms of mechanoradical production. We found that up to 14 times more mechanoradicals form by 'dry' milling, in comparison to those obtained by solvent-assisted grinding of the samples. This increase in the efficiency of mechanoradical generation might be attributed to the absence of solvent (or solution), which hinders efficient grinding, when it is present in the milling medium, by absorbing some of the mechanical energy. Another possible reason for the difference in the number of mechanoradicals formed through solvent-assisted and dry grinding might be a reaction of solvent with the initially formed, more reactive (carbon and alkoxy) radicals. In literature, DPPH was used to detect mechanoradicals formed on wet ground alumina and quartz $[17,18]$. In these studies, the solvent was reported to contribute in reactions with the formed mechanoradicals in alumina and quartz samples. In dry grinding, the produced mechanoradicals react with oxygen and form peroxy radicals, which do not react with the solvent of DPPH solution (acetonitrile) as we have shown in our previous study [14]. Below, we discuss the changes in morphology of cellulose during 'dry' and solvent-assisted milling of cotton and MCC and try to show the connection between these and the number of radicals obtained at the given milling conditions.

\subsection{Morphological changes in cryomilled cellulose samples monitored by scanning electron microscopy (SEM) analysis}

As expected, during milling, mechanical energy is absorbed by cellulose, chains break, and the particle size is reduced. (See supplementary information for the accompanying decrease in the molecular weight of the cellulose, Figs. S6 and S7, Table S1). Formed mechanoradicals reside on the freshly cleaved surfaces, so more efficient size reduction means more mechanoradicals, which we observe for solvent-assisted and 'dry' grinding of both MCC and cotton. After solvent-assisted cryomilling of the cotton and MCC with DPPH solutions for indicated times, cellulose samples were washed and dried in order to investigate morphological changes by SEM. SEM images (Fig. 3, S8 and S9) show, for both cotton and MCC samples, with increasing milling time, the particle sizes decrease.

Table 1

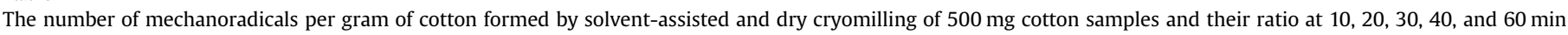
milling time.

\begin{tabular}{|c|c|c|c|}
\hline $\begin{array}{l}\text { Milling Time of Cotton } \\
\text { [min] }\end{array}$ & $\begin{array}{l}\text { Number of Radicals from Solvent-Assisted } \\
\text { Grinding }\end{array}$ & $\begin{array}{l}\text { Number of Radicals from Dry } \\
\text { Grinding }\end{array}$ & $\begin{array}{l}\text { The ratio of the Radicals from Dry Grinding to Solvent-Assisted } \\
\text { Grinding }\end{array}$ \\
\hline 10 & $5.22 \times 10^{17} \pm 1.59 \times 10^{17}$ & $1.82 \times 10^{18} \pm 1.80 \times 10^{17}$ & 3.5 \\
\hline 20 & $6.46 \times 10^{17} \pm 2.66 \times 10^{17}$ & $2.40 \times 10^{18} \pm 1.03 \times 10^{17}$ & 3.7 \\
\hline 30 & $1.26 \times 10^{18} \pm 2.58 \times 10^{17}$ & $2.65 \times 10^{18} \pm 2.98 \times 10^{17}$ & 2.1 \\
\hline 40 & $1.38 \times 10^{18} \pm 3.59 \times 10^{17}$ & $2.52 \times 10^{18} \pm 9.31 \times 10^{16}$ & 1.8 \\
\hline 60 & $1.26 \times 10^{18} \pm 3.30 \times 10^{17}$ & $3.26 \times 10^{18} \pm 4.25 \times 10^{17}$ & 2.6 \\
\hline
\end{tabular}


Table 2

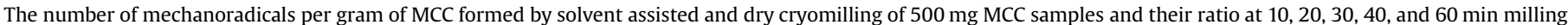
time.

\begin{tabular}{|c|c|c|c|}
\hline $\begin{array}{l}\text { Milling Time of MCC } \\
\text { [min] }\end{array}$ & $\begin{array}{l}\text { Number of Radicals from Solvent-Assisted } \\
\text { Grinding }\end{array}$ & $\begin{array}{l}\text { Number of Radicals from Dry } \\
\text { Grinding }\end{array}$ & $\begin{array}{l}\text { The ratio of the Radicals from Dry Grinding to Solvent-Assisted } \\
\text { Grinding }\end{array}$ \\
\hline 10 & $4.34 \times 10^{17} \pm 2.12 \times 10^{17}$ & $1.91 \times 10^{18} \pm 1.78 \times 10^{17}$ & 4.4 \\
\hline 20 & $2.02 \times 10^{17} \pm 1.30 \times 10^{17}$ & $2.91 \times 10^{18} \pm 1.46 \times 10^{16}$ & 14.4 \\
\hline 30 & $4.44 \times 10^{17} \pm 2.26 \times 10^{17}$ & $3.25 \times 10^{18} \pm 3.74 \times 10^{16}$ & 7.3 \\
\hline 40 & $6.66 \times 10^{17} \pm 1.59 \times 10^{17}$ & $3.53 \times 10^{18} \pm 6.44 \times 10^{16}$ & 5.3 \\
\hline 60 & $3.33 \times 10^{17} \pm 3.95 \times 10^{16}$ & $3.54 \times 10^{18} \pm 1.41 \times 10^{17}$ & 10.6 \\
\hline
\end{tabular}

a
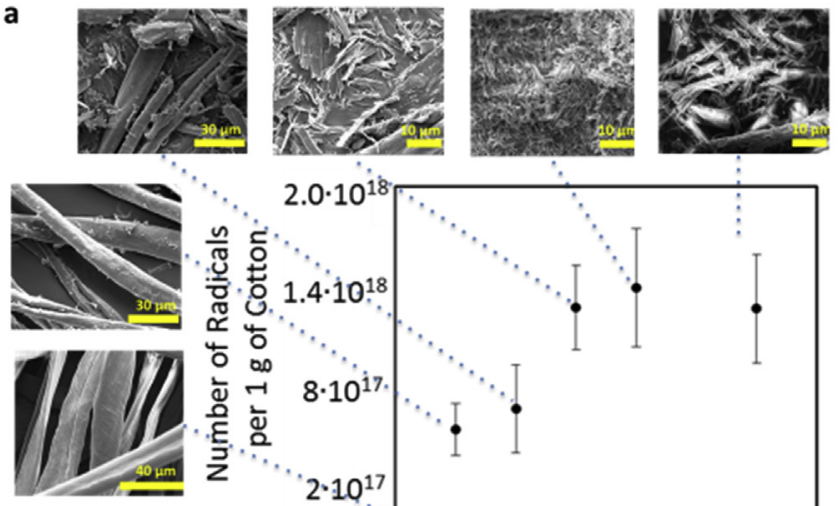

$2.0 \cdot 10^{18}$

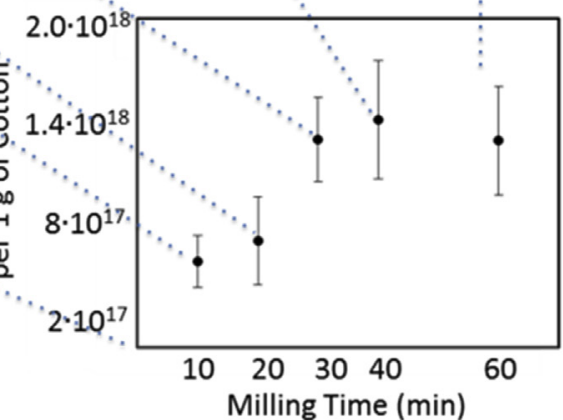

b
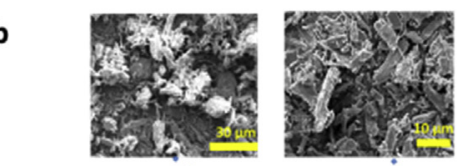

Milling Time $(\mathrm{min}$
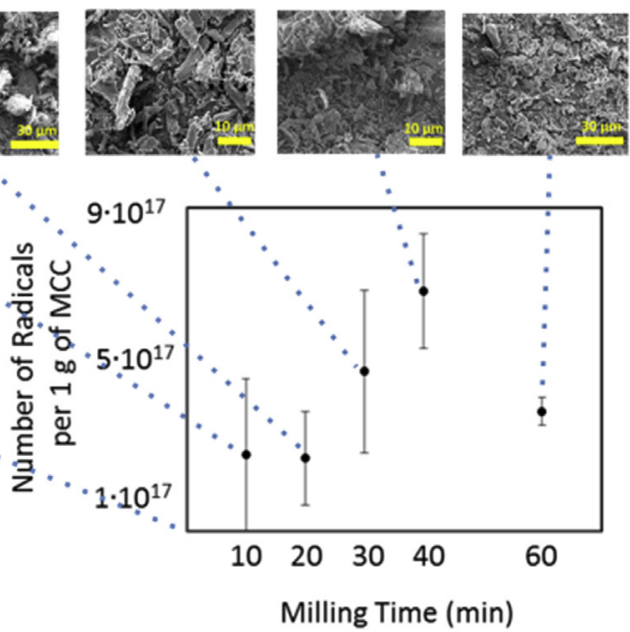

Fig. 3. Changes in the morphology of a) cotton and b) MCC samples in comparison to the number of mechanoradicals produced at the corresponding milling time. Samples were milled in the presence of acetonitrile for the given milling times, and the number of mechanoradicals was determined through the reaction with radical scavenger DPPH. In both (a) and (b), as the particle size decreases, there are more bond-breakages and hence more mechanoradicals. Since MCC (b) has a smaller initial particle size, the mechanoradical production levels out at earlier grinding times than in (a) for cotton.

However, the overall decrease is more pronounced for cotton, since cotton initially has millimeters-long-fibers with approximately $20.4 \mu \mathrm{m}$ width. MCC has shorter (ca. $50 \mu \mathrm{m}$ ) fibers of approximately $27 \mu \mathrm{m}$ width.

SEM images show that the particle size of the cellulose samples decreased faster in dry grinding method (Figs. S10 and S11). For example, the 'dry' milled cotton samples (Fig. S10) lost their fiber morphology even after milling for $10 \mathrm{~min}$ (cotton samples that were milled in the presence of solvent (Fig. S8) are still fibrous at this milling time), implying that mechanical energy upon impact was transferred more efficiently to the sample. The faster particle size reduction imaged by SEM can also be correlated with more radicals produced in dry grinding compared to solvent-assisted grinding (Tables 1 and 2).

\subsection{Changes in crystalline structure of cryomilled cellulose samples monitored by XRD}

XRD diffractograms of cotton and MCC show diffraction lines at 2Ө: $15.25^{\circ}, 16.88^{\circ}, 23.18^{\circ}, 34.89^{\circ}$ (for cotton) and $2 \Theta: 15.03^{\circ}$, $16.40^{\circ}, 22.54^{\circ}, 34.62^{\circ}$ (for MCC) before milling. These correspond to cellulose I crystalline structure and crystallographic planes of (1 1 $0),(110),(200)$, and (0 04$)$, respectively [30]. The main diffraction line approximately at $2 \Theta: 23.18^{\circ}$ for cotton and at $22.54^{\circ}$ for MCC samples is due to the lattice plane of (2 00 ), which arises from the distance between the sheets having hydrogen bonds. Moreover, the last diffraction line at approximately at $2 \ominus: 34.89^{\circ}$ for cotton and at $34.62^{\circ}$ for MCC samples corresponds to the lattice plane of $\left(\begin{array}{lll}0 & 0 & 4\end{array}\right)$, which results from the orientation along the fiber direction, which are affected by the alignment of chains into the fibrils [30]. As can be seen in both XRD patterns of cryomilled cotton and MCC samples in the presence of solvent (Fig. 4a and Fig. S12, respectively), there was no significant change in crystallinity (Table S2) after solvent-assisted cryomilling of the cellulose samples for indicated times (see SI for the details of crystallinity index analysis); for cotton and MCC samples percent crystallinity decreased slightly. Therefore, it can be concluded that solvent-assisted milling cannot provide efficient milling to disintegrate crystalline domains in both cotton and MCC. However, even in this case, there is still significant production of mechanoradicals (Tables 1 and 2), which means mechanical energy is absorbed chiefly by the amorphous parts of the cellulose samples and this is where the cellulose chains are broken to create the mechanoradicals.

On the other hand, percent crystallinity values drop even after short milling times for dry milled cotton and MCC samples (Fig. 4b and Fig. S13, respectively); a new broad band (approximately at 2Ө: $19^{\circ}$ ) appears for both type of cellulose sources implying the formation of amorphous cellulose. Using the Scherrer equation, the rapid decrease in average sizes of the crystalline regions can also be followed, however, only for the earlier milling times, when the samples have still high percent crystallinity. It was shown that transition from crystalline to amorphous takes place at around 10-20 min grinding time for $500 \mathrm{mg}$ cotton samples, and 5-10 min for $500 \mathrm{mg}$ MCC samples. (This transition time also depends on the amount of cellulose sample used, Fig. S14). It can be surmised that longer fibers of cotton (see SEM results in the previous section) give rise to longer transition time. All these results showed that in dry milling, mechanical energy upon impact affects not only the amorphous but also the crystalline regions and disintegrates the crystalline regions. Disintegrated chains are then cleaved more efficiently to produce mechanoradicals. Finally, all these are reflected as more mechanoradicals observed in ‘dry' milling (Tables 1 and 2). 

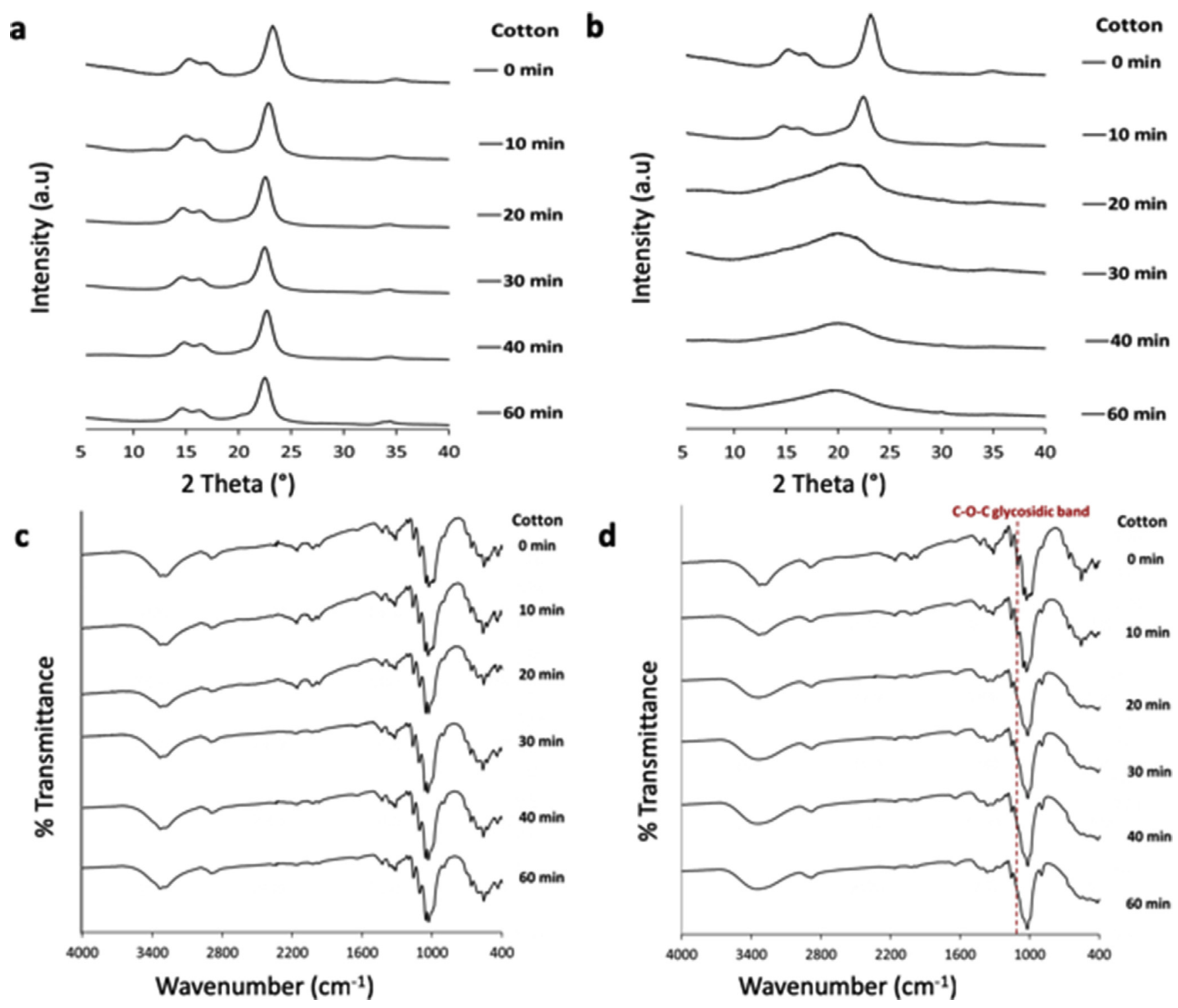

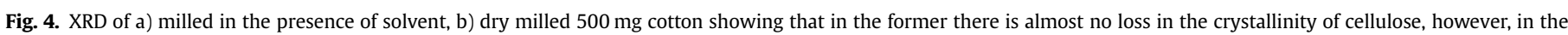

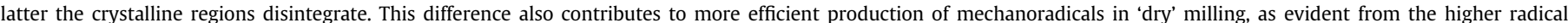

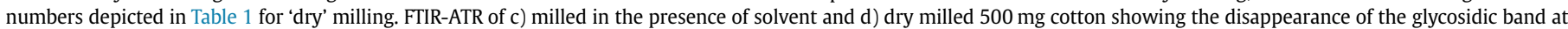

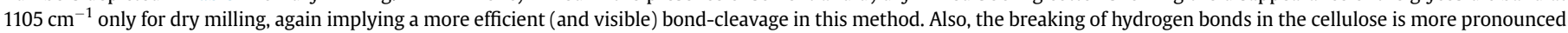
in the latter, as shown from the shift of the band for $\mathrm{OH}$ stretching to higher wavenumbers.

\subsection{Structural changes of cryomilled cellulose samples by FTIR-ATR spectroscopy analysis}

Bands observed in the ATR spectra of the cryomilled samples are assigned by comparing the experimental spectra with those in literature reports [31-34] (see SI, Table S3 and Fig. S15 for complete analysis). After solvent-assisted cryomilling of cotton and MCC samples for $60 \mathrm{~min}$ (Figs. 4c and S16), the bands due to both intra and intermolecular hydrogen bonds in cotton and MCC shifted slightly to higher wavenumbers, indicating a slight increase in free hydroxyl groups and decrease in the number of inter and intramolecular hydrogen bonds between cellulose chains [20,35-37]. In addition to the changes in $\mathrm{O}-\mathrm{H}$ stretching region, after cryomilling, intensity of bands visible as weak shoulders around $1000 \mathrm{~cm}^{-1}$ and $984 \mathrm{~cm}^{-1}$ (-CH- rocking, $\mathrm{C}-\mathrm{O}$ and ring stretching) [38-41] decrease slightly, implying breaking of the covalent bonds. These changes upon increasing milling time are much more pronounced in the case for 'dry' milling (Figs. 4d and S17). With dry cryomilling of cotton, the decrease in the weak shoulders around $1000 \mathrm{~cm}^{-1}$ and $984 \mathrm{~cm}^{-1}$ is observed around 10 min of milling time, which is less than 20 min needed to observe the same effect in the case of solvent-assisted milling. This decrease verifies again that in dry milling mechanical energy is more efficiently transferred to the sample. Finally, the most important band in the whole spectrum related to milling-induced changes is the $\mathrm{C}-\mathrm{O}-\mathrm{C}$ glycosidic stretching band around $1105 \mathrm{~cm}^{-1}$ [39,42-44]. The intensity of this band decreases gradually upon milling, indicating that, cryomilling of cellulose samples caused the breaking of glycosidic bonds in cellulose chains in addition to the breaking of intra and intermolecular hydrogen bonds. Like other changes observed in XRD and SEM analyses, these changes in IR bands due to mechanical treatment were seen after cryomilling of cotton samples for $20 \mathrm{~min}$ and cryomilling of MCC samples for $10 \mathrm{~min}$. It is clear from the comparison of band intensity of $\mathrm{C}-\mathrm{O}-\mathrm{C}$ glycosidic band; more 
glycosidic bonds were broken in dry grinding method than in the solvent-assisted grinding method.

\section{Conclusions}

With this study, we showed that morphological changes, initial size, and shape of the milled samples, their crystallinity effects the mechanoradical production significantly and this can also be tuned by adding a solvent in the medium; i.e., milling with solvent does not disintegrate the crystalline regions and mechanoradicals are produced chiefly in the amorphous regions. Solventless cryomilling produced more radicals under the same grinding conditions, due to a better reflection of mechanical energy on the fibers, and as a result, disintegration of crystalline regions. Dry grinding can break intra and intermolecular hydrogen bonds and covalent bonds, whereas solvent-assisted grinding is effective more on the hydrogen bonds. We believe that these findings will be useful in designing further mechanochemical reactions, where mechanoradicals (or free hydroxyl groups) act as reactants, in production of cellulose composites and blends. The idea that the morphological changes can affect the mechanochemical reactions can also be elaborated into the field general polymer mechanochemistry [45].

\section{Author contributions}

B.B. conceived the project idea, supervised and coordinated the work. Ö.L., J.K-.Y., M. E. and S.C.C. carried out the experiments. J.K-.Y. and B.B. wrote the manuscript with input from all authors. All authors have approved the final version of the manuscript.

\section{Acknowledgment}

This work was supported by Scientific and Technological Research Council of Turkey (TÜBiTAK) under project number 115Z452. BB acknowledges BAGEP 2016 award. We thank Prof. Levent Toppare and Prof. Ali Çırpan for their help in GPC measurements.

\section{Appendix A. Supplementary data}

Supplementary data to this article can be found online at https://doi.org/10.1016/j.polymdegradstab.2019.108945.

\section{References}

[1] D. Klemm, B. Heublein, H.-P. Fink, A. Bohn, Cellulose: fascinating biopolymer and sustainable raw material, Angew. Chem. Int. Ed. 44 (2005) 3358-3393. https://doi.org/10.1002/anie.200460587.

[2] F. Zhang, W. Qiu, L. Yang, T. Endo, T. Hirotsu, I. Science, Mechanochemical preparation and properties of a cellulose-polyethylene composite, J. Mater. Chem. 12 (2001) 24-26, https://doi.org/10.1039/b108255h.

[3] W. Zhang, C. Li, M. Liang, Y. Geng, C. Lu, Preparation of carboxylatefunctionalized cellulose via solvent-free mechanochemistry and its characterization as a biosorbent for removal of $\mathrm{Pb} 2+$ from aqueous solution, J. Hazard Mater. 181 (2010) 468-473, https://doi.org/10.1016/ j.jhazmat.2010.05.036.

[4] P. Huang, M. Wu, S. Kuga, D. Wang, D. Wu, Y. Huang, One-step dispersion of cellulose nanofibers by mechanochemical esterification in an organic solvent, ChemSusChem 5 (2012) 2319-2322, https://doi.org/10.1002/cssc.201200492.

[5] M. Sakaguchi, T. Ohura, T. Iwata, S. Takahashi, S. Akai, T. Kan, H. Murai, M. Fujiwara, O. Watanabe, M. Narita, Diblock copolymer of bacterial cellulose and poly(methylmethacrylate) initiated by chain-end-type radicals produced by mechanical scission of glycosidic linkages of bacterial cellulose, Biomacromolecules 11 (2010) 3059-3066, https://doi.org/10.1021/bm100879v.

[6] M. Sakaguchi, T. Ohura, T. Iwata, Y. Enomoto-Rogers, Nano cellulose particles covered with block copolymer of cellulose and methyl methacrylate produced by solid mechano chemical polymerization, Polym. Degrad. Stab. 97 (2012) 257-263, https://doi.org/10.1016/j.polymdegradstab.2011.12.022.

[7] T. Ohura, Y. Tsutaki, M. Sakaguchi, Novel synthesis of cellulose-based diblock copolymer of poly(hydroxyethyl methacrylate) by mechanochemical reaction, Sci. World J. 2014 (2014), https://doi.org/10.1155/2014/127506.
[8] I. Solala, U. Henniges, K.F. Pirker, T. Rosenau, A. Potthast, T. Vuorinen, Mechanochemical reactions of cellulose and styrene, Cellulose 22 (2015) 3217-3224, https://doi.org/10.1007/s10570-015-0724-X.

[9] D.N.-S. Hon, Formation and behavior of mechanoradicals in pulp cellulose, J. Appl. Polym. Sci. 23 (1979) 1487-1499, https://doi.org/10.1002 app.1979.070230519.

[10] M. Kuzuya, Y. Yamauchi, S. Kondo, Mechanolysis of glucose-based polysaccharides as studied by Electron Spin resonance 1, J. Phys. Chem. B 103 (1999) 8051-8059, https://doi.org/10.1021/jp984278d.

[11] I. Solala, Mechanoradical formation and its effects on birch kraft pulp during the preparation of nanofibrillated cellulose with Masuko refining, Holzforschung 66 (2012) 477-483.

[12] P.Y. Butyagin, I.V. Kolbanev, V.A. Radtsig, Electron paramagnetic resonance spectra of free radicals in the destruction products of solid polymers, Sov. Phys. Solid State 5 (1964) 1642-1644.

[13] M. Sakaguchi, J. Sohma, ESR evidence for main-chain scission produced by mechanical fracture of polymers at low temperature, J. Polym. Sci., Polym. Phys. Ed. 13 (n.d.) 1233-1245. doi:10.1002/pol.1975.180130614.

[14] H.T. Baytekin, B. Baytekin, B.A. Grzybowski, Mechanoradicals created in "polymeric sponges" drive reactions in aqueous media, Angew. Chem. Int. Ed. 51 (2012) 3596-3600, https://doi.org/10.1002/anie.201108110.

[15] B. Baytekin, H.T. Baytekin, B.A. Grzybowski, What really drives chemical reactions on contact charged surfaces? J. Am. Chem. Soc. 134 (2012) 7223-7226, https://doi.org/10.1021/ja300925h.

[16] H.T. Baytekin, B. Baytekin, T.M. Hermans, B. Kowalczyk, B.A. Grzybowski, Control of surface charges by radicals as a principle of antistatic polymers protecting electronic circuitry, Science 341 (2013) 1368-1371, https:// doi.org/10.1126/science.1241326.

[17] C. Damm, W. Peukert, Mechano-chemical radical formation and polymerization initiation during wet grinding of alumina, J. Colloid Interface Sci. 363 (2011) 386-392, https://doi.org/10.1016/j.jcis.2011.07.020.

[18] F. Delogu, Mechanochemical behavior of surface radicals in ground quartz J. Phys. Chem. C 115 (2011) 21230-21235, https://doi.org/10.1021/ jp206354p.

[19] H.T. Baytekin, B. Baytekin, S. Huda, Z. Yavuz, B.A. Grzybowski, Mechanochemical activation and patterning of an adhesive surface toward nanoparticle deposition, J. Am. Chem. Soc. 137 (2015) 1726-1729, https://doi.org/ $10.1021 / \mathrm{ja} 507983 \mathrm{x}$

[20] M. Ago, T. Endo, K. Okajima, Effect of solvent on morphological and structura change of cellulose under ball-milling, Polym. J. 39 (2007) 435-441, https: / doi.org/10.1295/polymj.PJ2006096.

[21] M. Tsuzuki, N. Shiraishi, T. Yokota, Rapid acetylation of native cellulose by TFAA and characterization of the products, J. Appl. Polym. Sci. 25 (1980) 2567-2572, https://doi.org/10.1002/app.1980.070251113.

[22] M. Sakaguchi, M. Makino, T. Ohura, T. Iwata, Mechanoanions produced by mechanical fracture of bacterial cellulose: ionic nature of glycosidic linkage and electrostatic charging, J. Phys. Chem. A 116 (2012) 9872-9877, https:// doi.org/10.1021/jp306261k.

[23] S. Shimada, A. Suzuki, M. Sakaguchi, Y. Hori, Molecular motion of chain end peroxy radicals of polyethylene molecules tethered on a fresh surface of poly(tetrafluoroethylene), Macromolecules 29 (1996) 973-977, https:// doi.org/10.1021/ma951139a.

[24] B. Stefanovic, K.F. Pirker, T. Rosenau, A. Potthast, Effects of tribochemical treatments on the integrity of cellulose, Carbohydr. Polym. 111 (2014) 688-699, https://doi.org/10.1016/j.carbpol.2014.05.011.

[25] M. Sakaguchi, T. Iwamura, K. Yamamoto, Y. Miwa, S. Shimada, M. Sakai, Molecular mobility of peroxy radicals at the ends of nonisolated polystyrene chains tethered on the solid surface of poly(tetrafluoroethylene) in a vacuum, Macromolecules 41 (2008) 253-257, https://doi.org/10.1021/ma701925v.

[26] E.A. Nikitina, V.D. Khavryutchenko, E.F. Sheka, H. Barthel, J. Weis, Deformation of poly(dimethylsiloxane) oligomers under uniaxial Tension: quantum chemical view, J. Phys. Chem. A 103 (1999) 11355-11365, https://doi.org/ $10.1021 / j p 990221 \mathrm{v}$.

[27] S.N. Zhurkov, V.A. Zakrevskyi, V.E. Korsukov, V.S. Kuksenko, Mechanism of submicrocrack generation in stressed polymers, J. Polym. Sci., Part A Polym. Phys. 10 (1972) 1509-1520, https://doi.org/10.1002/pol.1972.160100808.

[28] P.Ju Butiagin, The decay of free radicals in polymer media, Pure Appl. Chem. 30 (1972) 57-76, https://doi.org/10.1351/pac197230010057.

[29] J. Sohma, Radical migration as an elementary process in degradation, Pure Appl. Chem. 55 (1983) 1595-1601, https://doi.org/10.1351/ pac198355101595.

[30] A. Thygesen, J. Oddershede, H. Lilholt, A.B. Thomsen, K. Ståhl, On the determination of crystallinity and cellulose content in plant fibres, Cellulose 12 (2005) 563, https://doi.org/10.1007/s10570-005-9001-8.

[31] D. Fengel, Influence of water on the $\mathrm{OH}$ valency range in deconvoluted FTIR spectra of cellulose, Holzforschung 47 (1993) 103-108, https://doi.org/ 10.1515/hfsg.1993.47.2.103.

[32] E.P. Kalutskaya, S.S. Gusev, An infrared spectroscopic investigation of the hydration of cellulose, Polym. Sci. U. S. S. R. 22 (1980) 550-556, https:// doi.org/10.1016/0032-3950(80)90378-0.

[33] M. Schwanninger, J.C. Rodrigues, H. Pereira, B. Hinterstoisser, Effects of shorttime vibratory ball milling on the shape of FT-IR spectra of wood and cellulose, Vib. Spectrosc. 36 (2004) 23-40, https://doi.org/10.1016/ j.vibspec.2004.02.003.

[34] F.G. Pearson, R.H. Marchessault, C.Y. Liang, Infrared spectra of crystalline 
polysaccharides. V. Chitin, J. Polym. Sci. 43 (1960) 101-116, https://doi.org/ 10.1002/pol.1960.1204314109.

[35] A.S. Khan, Z. Man, M.A. Bustam, C.F. Kait, M.I. Khan, N. Muhammad, A. Nasrullah, Z. Ullah, P. Ahmad, Impact of ball-milling pretreatment on pyrolysis behavior and kinetics of crystalline cellulose, Waste Biomass Valorization 7 (2016) 571-581, https://doi.org/10.1007/s12649-015-9460-6.

[36] D. Ciolacu, F. Ciolacu, V. Popa, Amorphous cellulose - structure and characterization, Cellul. Chem. Technol. 45 (2011) 13-21.

[37] A. Selarka, R. Baney, S. Matthews, Processing of microcrystalline cellulose in dimethyl sulfoxide, urea and supercritical carbon dioxide, Carbohydr. Polym. 93 (2013) 698-708, https://doi.org/10.1016/j.carbpol.2012.11.101.

[38] C.Y. Liang, R.H. Marchessault, Infrared spectra of crystalline polysaccharides. II. Native celluloses in the region from 640 to $1700 \mathrm{~cm}^{-1}$, J. Polym. Sci. 39 (2003) 269-278, https://doi.org/10.1002/pol.1959.1203913521.

[39] P. Garside, P. Wyeth, Identification of cellulosic fibres by FTIR spectroscopy thread and single fibre analysis by attenuated total reflectance, Stud. Conserv. 48 (2003) 269-275, https://doi.org/10.1179/sic.2003.48.4.269.

[40] M.-F. Li, Y.-M. Fan, F. Xu, R.-C. Sun, X.-L. Zhang, Cold sodium hydroxide/urea based pretreatment of bamboo for bioethanol production: characterization of the cellulose rich fraction, Ind. Crops Prod. 32 (2010) 551-559, https:/ doi.org/10.1016/j.indcrop.2010.07.004.
[41] N. Abidi, E. Hequet, L. Cabrales, Applications of fourier transform infrared spectroscopy to study cotton fibers, in: Fourier Transform. - New Anal. Approaches FTIR Strateg., InTech, 2011.

[42] M.K.M. Haafiz, A. Hassan, A.K. H.p.s, A.F. Owolabi, M.M. Marliana, R. Arjmandi, I.M. Inuwa, M.R. Nurul Fazita, M.H. Hussin, 10 - cellulose nanowhiskers from oil palm empty fruit bunch biomass as green fillers, in: Cellul.-Reinf. Nanofibre Compos., Woodhead Publishing, 2017, pp. 241-259, https://doi.org/10.1016/ B978-0-08-100957-4.00010-3.

[43] S. Chang, B. Condon, J.V. Edwards, Preparation and characterization of aminobenzyl cellulose by two step synthesis from native cellulose, Fibers Polym. 11 (2010) 1101-1105, https://doi.org/10.1007/s12221-010-1101-x.

[44] R.L. Oliveira, J.G. Vieira, H.S. Barud, R.M.N. Assunção, G.R. Filho, S.J.L. Ribeiro, Y. Messadeqq, R.L. Oliveira, J.G. Vieira, H.S. Barud, R.M.N. Assunção, G.R. Filho, S.J.L. Ribeiro, Y. Messadeqq, Synthesis and characterization of methylcellulose produced from bacterial cellulose under heterogeneous condition, J. Braz. Chem. Soc. 26 (2015) 1861-1870, https://doi.org/10.5935/01035053.20150163.

[45] K.M. Wiggins, J.N. Brantley, C.W. Bielawski, Methods for activating and characterizing mechanically responsive polymers, Chem. Soc. Rev. 42 (2013) 7130-7147, https://doi.org/10.1039/C3CS35493H. 